\title{
A hydrazine-free Wolff-Kishner reaction suitable for an undergraduate laboratory
}

Article

Accepted Version

Cranwell, P. B. and Russell, A. T. (2016) A hydrazine-free Wolff-Kishner reaction suitable for an undergraduate laboratory. Journal of Chemical Education, 93 (5). pp. 949952. ISSN 0021-9584 doi:

https://doi.org/10.1021/acs.jchemed.5b00954 Available at https://centaur.reading.ac.uk/65801/

It is advisable to refer to the publisher's version if you intend to cite from the work. See Guidance on citing.

Published version at: http://dx.doi.org/10.1021/acs.jchemed.5b00954

To link to this article DOI: http://dx.doi.org/10.1021/acs.jchemed.5b00954

Publisher: The American Chemical Society

All outputs in CentAUR are protected by Intellectual Property Rights law, including copyright law. Copyright and IPR is retained by the creators or other copyright holders. Terms and conditions for use of this material are defined in the End User Agreement.

\section{www.reading.ac.uk/centaur}

\section{CentAUR}

Central Archive at the University of Reading 
Reading's research outputs online 


\section{A Hydrazine-Free Wolff-Kishner Reaction Suitable for an Undergraduate Laboratory}

Philippa B. Cranwell,* Andrew T. Russell.

Department of Chemistry, University of Reading, Whiteknights, Reading,

5 RG6 6AD, UK

\section{ABSTRACT}

A Wolff-Kishner reaction that does not require hydrazine has been

developed. The reaction sequence has two steps; formation of a

carbomethoxyhydrazone from methyl hydrazinocarboxylate and

10 acetophenone, then decomposition of this intermediate by treatment with

potassium hydroxide in triethylene glycol. Purification is by filtration

through a plug of silica encased in the barrel of a plastic syringe. The

reaction sequence can be completed within a day-long laboratory class $(8$ hours). 

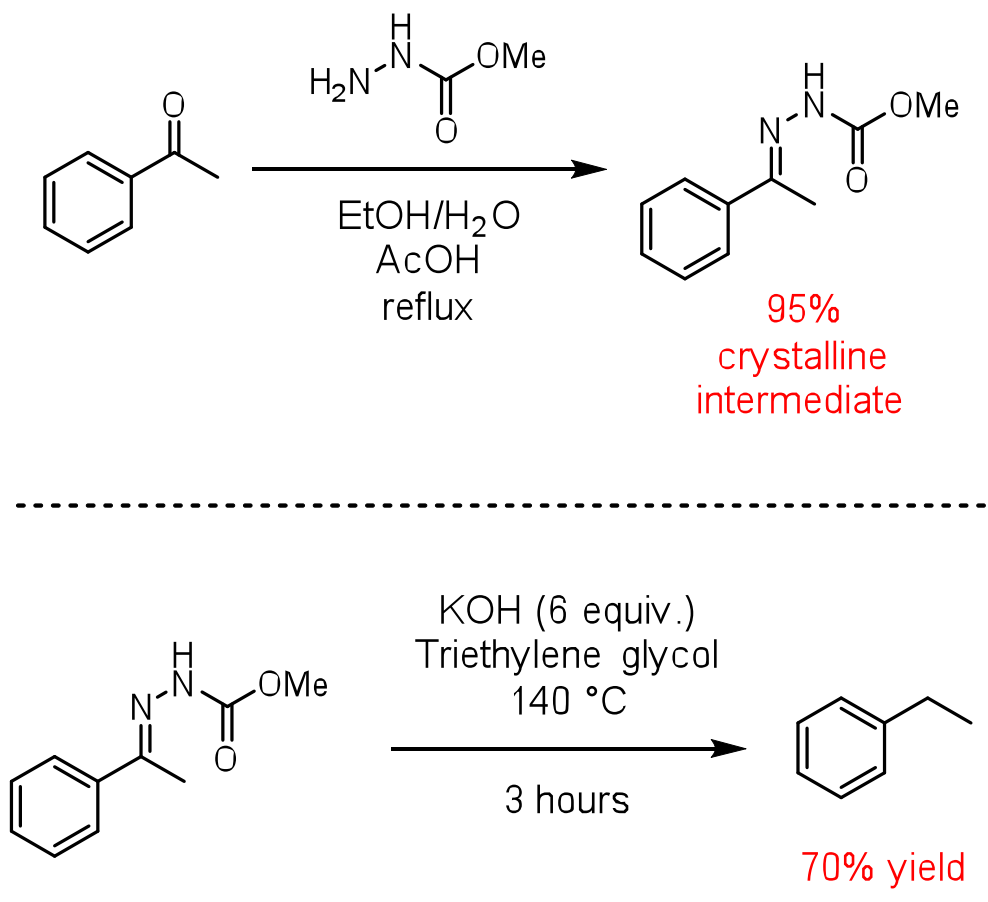

\section{KEYWORDS}

Second year undergraduate, laboratory instruction, organic chemistry, safety/hazards, hands on learning/manipulatives, aldehydes/ketones, reduction, synthesis.

The Wolff-Kishner reaction, discovered independently by Kishner in $1911^{1}$ and Wolff in $1912,^{2}$ has become a standard method of reducing aldehydes and ketones to their corresponding methylene unit, although early work by Staudinger should not be forgotten ${ }^{3}$ (Scheme 1). Modification of this initial work, by Huang-Minlon, ${ }^{4}$ led to a procedure 
that was widely applicable to modern synthesis as well as a procedure suitable for an undergraduate practical class. ${ }^{5}$ Further modifications have provided a range of variants, all of which have all proven useful. 5, 6
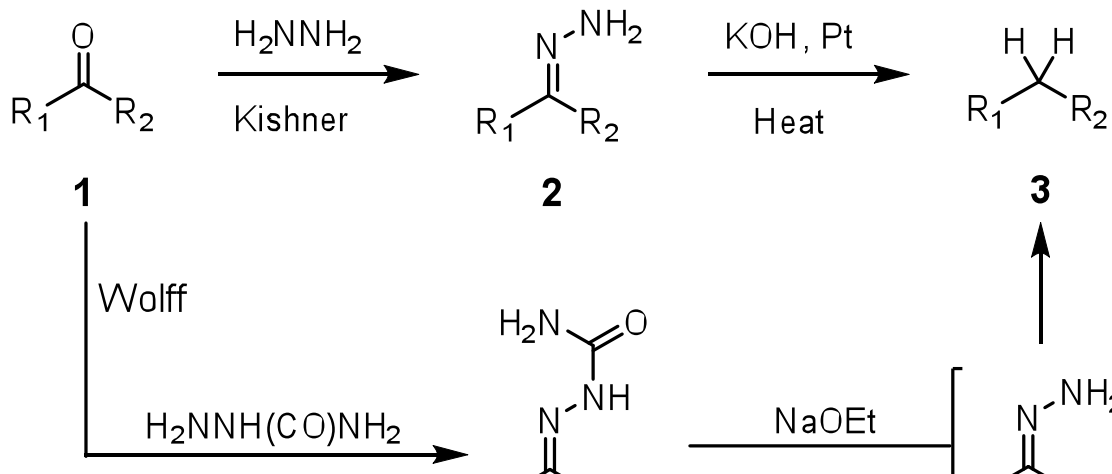

2

\section{3}<smiles>[R]C([R])=NNC(N)=O</smiles>

4

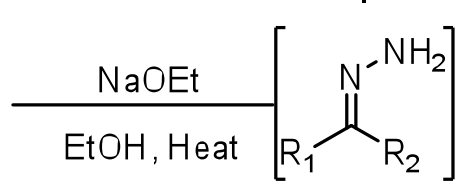

5

Scheme 1: General Wolff-Kishner Reaction

However, one significant draw-back of the Huang-Minlon variant of the Wolff-Kishner reaction is the requirement for hydrazine, an extremely toxic reagent, in stoichiometric quantities. Studies upon the effects of hydrazine have shown that acute expose leads to liver, kidney and CNS damage in humans. Chronic exposure by inhalation has shown effects in the liver, spleen and thyroid in animals as well as increased incidences of lung, nasal cavity and liver tumors. These effects have led the U.S.

40 Environmental Protection Agency to deem hydrazine as Group 2B, a probable human carcinogen. ${ }^{7}$ In terms of general research, this is not usually a problem because safeguards can be easily put in place to minimize exposure. However, in an undergraduate laboratory situation 
this is undesirable and the substitution of toxic hydrazine by another,

less toxic, hydrazine equivalent is clearly an advantage. In order to address these issues, work towards developing an alternative procedure suitable for an undergraduate laboratory was undertaken that has ultimately led to the development of a generally applicable, hydrazinefree, Wolff-Kishner procedure. ${ }^{8}$

\section{EXPERIMENTAL DETAILS}

This experiment is designed for students who have already experienced a year of undergraduate practical chemistry, and, in our Department, sits within a 5-week organic chemistry laboratory course. For the duration of this course, students work in pairs in a day-long laboratory class $(8 \mathrm{~h})$.

55 Before each laboratory class, students complete a risk assessment and are expected to complete an additional online test. During the tests students are asked a series of questions designed to encourage them to think about the reaction they are going to undertake, and ultimately enhance student engagement with the laboratory class. The pedagogic goals of this experiment are as follows: to encourage students to think about the toxicity of chemicals they are using and therefore the use of alternatives, to consider time management when undertaking an experiment, to introduce them to flash column chromatography, and to teach students to work with volatile compounds. 
Students start by preparing the carbomethoxyhydrazone. This is achieved by addition of methyl hydrazinocarboxylate to acetophenone in ethanol with an acetic acid catalyst, then heating the reaction at reflux for 30 minutes, Scheme 2. After this time the reaction is cooled, the precipitated product collected by suction filtration through a Büchner

70 funnel, washed with 95\% EtOH and dried. The students collect IR and melting point data for this product. They are provided with ${ }^{1} \mathrm{H}$ NMR spectra (with and without $\mathrm{D}_{2} \mathrm{O}$ shake) that they are expected to interpret fully as part of their laboratory report.<smiles>CC(=O)c1ccccc1</smiles>
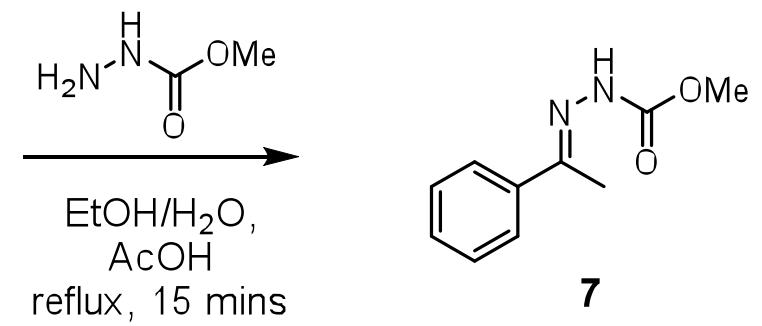

crystalline intermediate $95 \%$ yield

Scheme 2: Preparation of the carbomethoxyhydrazone intermediate 5

The second step starts with students dissolving $\mathrm{KOH}$ in triethylene glycol, adding the carbomethoxyhydrazone in one portion and heating the reaction at $140{ }^{\circ} \mathrm{C}$; slightly above the boiling point of ethyl benzene $\left(136^{\circ} \mathrm{C}\right)$, Scheme 3. After a short time, effervescence is observed that we attribute to $\mathrm{CO}_{2}$ formation (see below). 


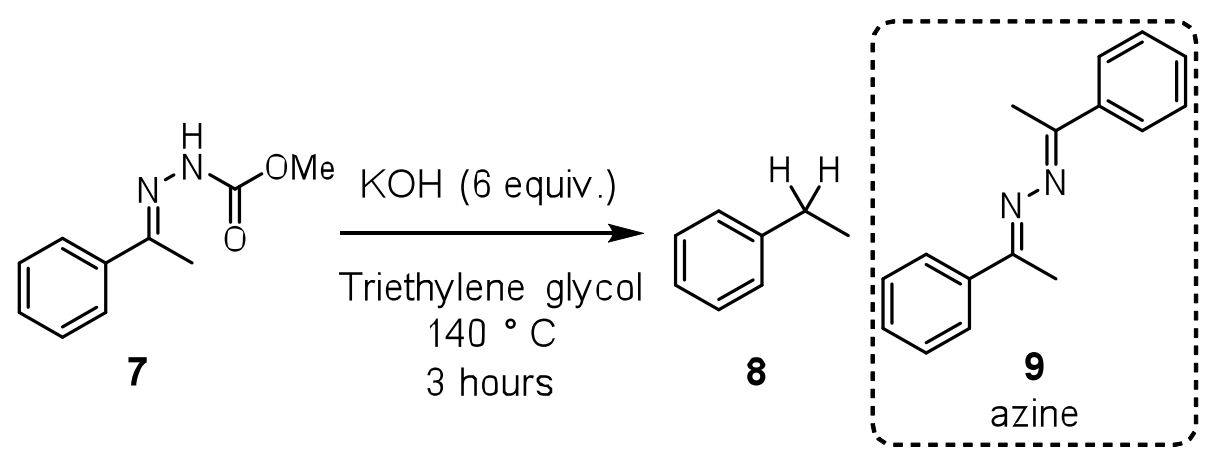

Scheme 3: Degradation of the carbomethoxyhydrazone intermediate 7

The reaction is complete within 3 hours, at which point it is allowed to cool to ambient temperature and diluted with water. The product is extracted into diethyl ether, the organic phase dried $\left(\mathrm{MgSO}_{4}\right)$, filtered and the solvent removed under reduced pressure. Prior to solvent removal, students add a small volume of acetone $(1 \mathrm{~mL})$ as a safety measure in case there is any free-hydrazone present that could lead to azine $\mathbf{9}$ formation and, ultimately, hydrazine production upon concentration. Finally, purification is achieved by passing the crude material through a short plug of silica encased in a plastic syringe body, ${ }^{9}$ eluting with pentane. The volatile product is isolated as a yellow oil. We attribute the yellow color to the formation of azine 9 (up to 5\%) during the reaction itself, rather than after work-up. Students collect ${ }^{1} \mathrm{H}$ NMR data for this 95 product and are provided with ${ }^{13} \mathrm{C}$ and DEPT135 NMR data that they are expected to interpret fully. 


\section{HAZARDS}

Safety glasses, nitrile gloves, and a laboratory coat should be worn at all times in the laboratory and the reactions should all be undertaken in

100 a fume cupboard. All hazardous materials should be used and disposed of in accordance with local health and safety rules. Acetophenone is harmful if swallowed and can cause serious eye irritation. Ethanol is highly flammable and can cause serious eye irritation. Methyl hydrazinocarboxylate cases skin irritation, serious eye irritation and may cause respiratory irritation. Glacial acetic acid is flammable and can cause severe skin burns and eye damage. The intermediate carbomethoxyhydrazone should be treated as toxic. Triethylene glycol has no known hazards but should be treated as toxic. Potassium hydroxide may be corrosive to metals, is harmful if swallowed and causes severe burns and eye damage. Ethyl benzene is highly flammable and harmful if inhaled. Diethyl ether is extremely flammable, harmful if swallowed and may cause drowsiness or dizziness. Magnesium sulfate has no known hazards but should be treated as toxic. Acetone is highly flammable, can cause serious eye irritation and may cause drowsiness or dizziness. Pentane is highly flammable, may be fatal if swallowed or inhaled, may cause drowsiness or dizziness and is toxic to aquatic life. Silica gel is harmful if inhaled and so should only be used in a fume cupboard. Deuterated chloroform is harmful if swallowed, causes skin 
and eye irritation, is toxic if inhaled, is a suspected carcinogen, is a teratogen, and can cause damage to organs through prolonged or repeated exposure. The second step of this reaction liberates a gas, therefore when stirring it is essential that the magnetic stirrer bar is large enough to allow effective stirring to occur. An oval stirrer bar is best for this. Concentration of the reaction should be undertaken in a fume hood to avoid any possible exposure to hydrazine.

\section{RESULTS}

Of the 40 students (20 pairs) who undertook the reaction, all prepared enough material to be able to characterize the intermediate carbomethoxyhydrazone. The average yield was $90 \%$ for this step, with 130 student yields ranging from $72 \%$ to quantitative. The second step, degradation of the intermediate, was also successful and student yields ranged from $22 \%$ to $94 \%$. The average yield for this step was $57 \%$, comparable to the instructor yield of $70 \%$.

During preparation of the carbomethoxyhydrazone, the product occasionally precipitated instantly after addition of the acetic acid. When this happened students were told to heat the reaction for 15 minutes then collect the precipitate. The yield of the intermediate obtained by students was good and all of them had reached this point after 2 hours. When students had yields greater than $100 \%$ it was due to residual ethanol which evaporated if the sample was left open to air. Purity was 
also good, as the NMR data shows (see supporting information), and all melting points were in agreement with published data. ${ }^{7}$ The instructors ensured that all students had started the reduction step before lunch to allow for the 3-hour heating step, during which time students collected data for their intermediate. It was important during the reaction that the $\mathrm{KOH}$ was pre-dissolved in the triethylene glycol otherwise the reaction did not run to completion in the time allocated. Approximately 10 minutes after initial addition of the carbomethoxyhydrazone intermediate to the basic solution, rapid bubbling was observed that we attribute to evolution of $\mathrm{CO}_{2}$ from decomposition of the carbomethoxyhydrazone followed by slower formation of nitrogen (Figure 1). As the students used a $250 \mathrm{~mL}$ round-bottomed flask equipped with a large oval stirrer bar this did not cause any issues. If bubbling did become excessive, the flask was simply lifted out of the heat until the foam subsided, and then 155 placed back onto the heat. Over time, the ethylbenzene product could be seen refluxing inside the flask, providing a visual cue that the reaction was proceeding. 


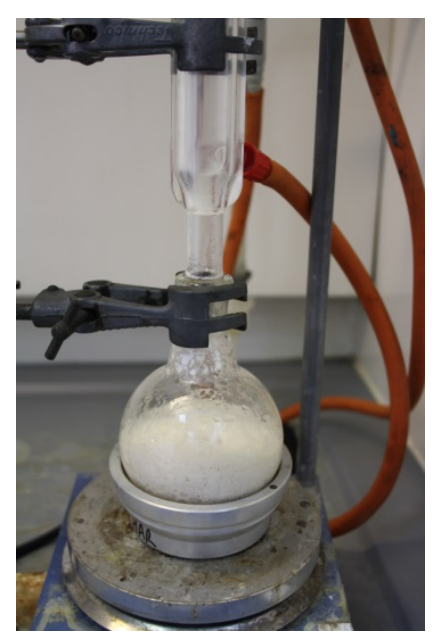

Figure 1: Bubbles formed during the reaction.

The extraction did not provide any difficulties although students had to be reminded to allow the reaction to cool completely before addition of diethyl ether, and also to vent the separating funnel frequently, through the tap, during the work-up to prevent pressure build-up. Prior to solvent removal, students were instructed to add $1 \mathrm{~mL}$ of acetone to the crude material as a safety measure, just in case there was any residual hydrazone $\mathbf{2}$ present (as noted above, by self-condensation of $\mathbf{9}$ hydrazine would result). The solvent was removed with a rotary evaporator in a fume hood as an additional precaution. As part of the pre-laboratory test, students were asked to look up the boiling point of ethylbenzene then, using a nomograph, estimate its boiling point at $20 \mathrm{mmHg}$ (as a reasonable approximation to the operating pressure inside our rotary evaporators). Responding to the students' estimated boiling point, during 
removal of the solvent students were asked to consider the value of having the water bath on the rotary evaporator cold, to avoid any product losses through evaporation.

${ }^{1} \mathrm{H}$ NMR spectra of the crude material obtained at this stage were recorded for some of the students' reactions and showed that they had proceeded to completion. In some cases there was minimal azine formation. This was evidenced by a bright yellow solid forming in the flask during solvent removal. Additionally, variable quantities of diethyl ether were present depending upon the care taken with rotary evaporation.

Purification was carried out by flash column chromatography through a short plug of silica encased in a $20 \mathrm{~mL}$ syringe..$^{9}$ A B19 air inlet adaptor was fitted inside the barrel so that the solvent could be eluted using bellows (Figure 2). Occasionally, there was an orange band at the base of the column.

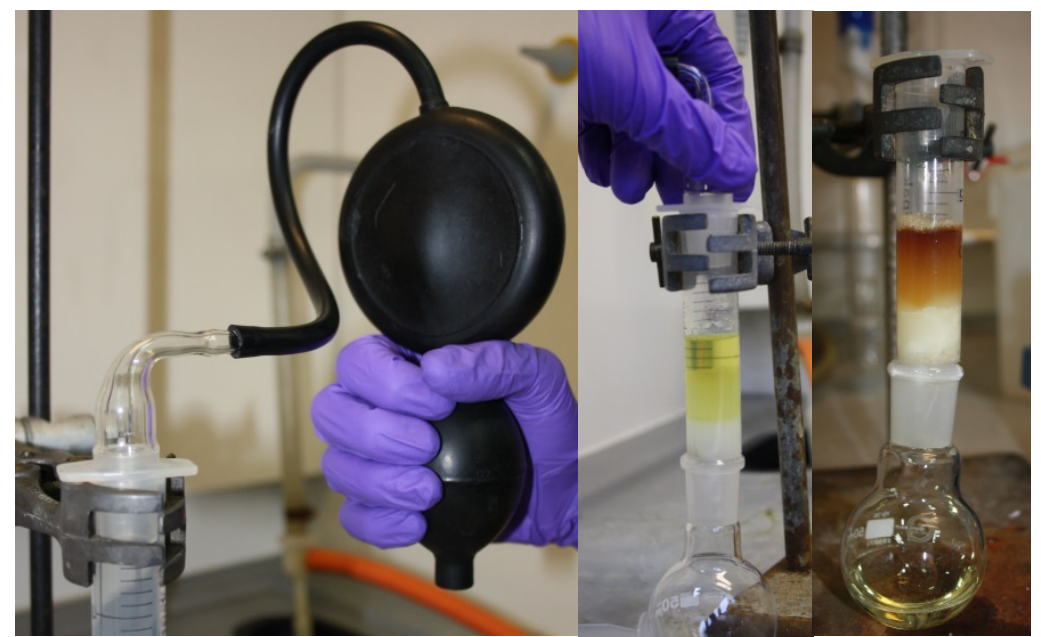


Figure 2: Photograph of silica gel column the students used to purify their product.

Removal of the solvent was achieved on a rotary evaporator and again students were reminded of the need to ensure the water bath was cold. In the students' product NMR spectra, the only impurities observed were residual pentane and, occasionally, traces of the azine that was formed during the heating step and could not be avoided (see Supporting Information). Low yields in some cases could be attributed to heating the water-bath, leading to losses due to the volatility of the product.

\section{CONCLUSION}

200 A Wolff-Kishner reaction that avoids the use of hydrazine has been developed and the pedagogic goals we set were achieved. All students were able to prepare the intermediate in high yield and purity and also prepared ethyl benzene within the allocated laboratory period, addressing the time management goal $(8 \mathrm{~h})$. The two distinct steps in the reaction sequence allow for the reaction to be split over a longer period if required.

The second step provided students with the chance to learn how to work with volatile compounds which provided a valuable assessment tool for practical ability; less diligent students achieved lower yields due to the volatility of the product. Purification through a silica gel plug taught 210 students about flash column chromatography as a means for product purification, and the equipment we used was cheap and simple to set up. 
In terms of safety, this reaction is advantageous because it avoids the use of hydrazine, an extremely toxic chemical.

\section{ASSOCIATED CONTENT}

Supporting Information [required for the manuscript types Laboratory Experiment and Activity]

Detailed reagent and supply list, protocols for laboratory instructors, student handouts and demonstration videos, and analytical data for products (including melting points, NMR data, and IR spectra). This material is available via the Internet at http://pubs.acs.org.

\section{AUTHOR INFORMATION}

Corresponding Author

*E-mail: p.b.cranwell@reading.ac.uk

\section{ACKNOWLEDGMENT}

The University of Reading Department of Chemistry undergraduate teaching laboratories are acknowledged for their help when piloting this practical class.

\section{REFERENCES}

1. Kishner, N. Catalytic Decomposition of alkylhydrazines to give organic compounds containing carbon (title translated from Russian), J. Russ. Chem. Soc. 1911, 43, 582 - 595.

2. Wolff, L. Methode zum Ersatz des Sauerstoffatoms der Ketone und Aldehyde durch Wasserstoff. Ann. Chem. 1912, 394, 86 - 108.

3. Staudinger, H.; Kupfer, O. Versuche zur Darstellung von Methylenederivate. Ber. Dtsch.Chem. Ges. 1911, 44 (3), 2194 - 2197. Staudinger, H.; Gaule, A. Versuche zur Herstellung isomerer Diazoverbindungen bezw. Hydrazone. Chem. Ber. 1916, 49 (2), 1961 - 1968. 
4. (a) Huang-Minlon. A Simple Modification to the Wolff-Kishner Reduction. J. Am. Chem. Soc. 1946, 68 (12), 2487 - 2488. (b) Huang-Minlon. Reduction of Steroid Ketones and other Carbonyl Compounds by Modified Wolff-Kishner Method. J. Am. Chem. Soc. 1949, 71 (10), $3301-3303$.

5. Soriano, D. A. Example of the Wolff-Kishner reduction procedure suitable for an undergraduate organic lab experiment: Preparation of oxindole. J. Chem. Educ. 1993, 70 (4), 332.

6. (a) Kuethe, J. T.; Childers, K. G.; Peng, Z.; Journet, M.; Humphrey, G. R.; Vickery, T.; Bachert, D.; Lam, T. T. A Practical Kilogram-Scale Implementation of the Wolff-Kishner Reduction. Org. Proc. Res. \& Dev. 2009, 13 (3), 576 - 580. (b) Cram, D. J.; Sahyun, M. R. V.; Room Temperature Wolff-Kishner Reduction and Cope Elimination Reactions. J. Am. Chem. Soc. 1962, 84 (9), 1734 - 1735. (c) Furrow, M. E.; Myers, A. G. Practical Procedures for the Preparation of $\mathrm{N}$-tert-Butyldimethylsilylhydrazones and Their Use in Modified Wolff-Kishner Reductions and in the Synthesis of Vinyl Halides and gem-Dihalides. J. Am. Chem. Soc. 2004, 126 (17), 5436 - 5445. (d) Cook, A. H.; Linstead, R. P. Fused carbon rings. Part II. The synthesis of cis- $\alpha-0: 3: 3-$ bicycloOctanone and related compounds. J. Chem. Soc. 1934, 946 956. (e) Quast, H.; Ivanova, S.; Peters, E-M.; Peters, K. Ring Expansion of 2Alkylidenedihydroquinolines to 2-Iminodihydro-1-benzazepines by Phenyl, Methanesulphonyl, and Trifluoromethanesulphonyl Azide. Eur. J. Org. Chem. 2000, (3), 507 520. (f) Zengin, G.; Huffman, J. W. Synthesis of $N$-Alkylnaphthalenes via Semicarbazones. Turk. J. Chem. 2006, 30, 139 - 144. (g) Todd, D. The Wolff-Kishner Reduction. II. The Effect of Alkali on N-Substituted Hydrazones. J. Am. Chem. Soc. 1949, 71 (4), 1356 - 1358. (h) Seibert, W. Über den Mechanismus der Reaktion von Kishner-Wolff-Staudinger, I. Mitteilung. Chem. Ber. 1947, 80 (6), 494 - 502. (i) Seibert, W. Über den Mechanismus der Reaktion von Kishner-Wolff-Staudinger, II. Mitteilung. Chem. Ber. 1948, 81 (3), 266 - 277.

7. United States Environment Protection Agency. http://www.epa.gov/iris (accessed January 18, 2016)

8. (a) Cranwell, P. B.; Russell, A. T.; Smith, C. D. Methyl Hydrazinocarboxylate as a Practical Alternative to Hydrazine in the Wolff-Kishner Reaction. Synlett 2016, 27 (1), 131 - 135. (b) 
ed-20XX-XXXXXX

Ponaras, A. A. A New Variant of the Claisen Rearrangement Capable of Creating the Bond Between Two Quaternary Centers. J. Org. Chem. 1983, 48 (21), 3866 - 3868.

9. Cranwell, P. B.; Peterson, A. M.; Littlefield, B. T. R.; Russell, A. T. An Operationally Simple Sonogashira Reaction for an Undergraduate Organic Chemistry Laboratory Class. J. Chem. Educ. 2015, 92 (6), 1110-1114. 